\title{
CROSSED PINNING VERSUS TWO LATERAL WIRES IN THE MANAGEMENT OF DISPLACED SUPRACONDYLAR HUMERUS FRACTURES IN CHILDREN By
}

\author{
Alaa AM El-Ngehy, Amr M Eladawy, Walid F El-Sharkawi and Muhammed MG Naeem \\ Orthopedic Surgery Department, Faculty of Medicine, Zagazig University
}

\begin{abstract}
Introduction: Closed reduction of supracondylar humerus fractures with $\mathrm{K}$-wires has become the standard line of management with different opinions regarding the technique that is utilized.

Aim: To compare the functional and radiological outcomes of lateral and cross pinning technique in supracondylar fractures of humerus in children.

Materials and Methods: A prospective study with 57 cases of displaced fracture supracondylar humerus, treated by lateral (Group A $n=28$ ) and cross pinning (Group B n=29), was conducted between May 2013 and May 2015. Independent sample student's t-test was done to assess the parameters like age, follow-up and duration of surgery. The results were expressed as mean with standard deviation and $\mathrm{p}<0.05$ was considered as statistically significant.

Results: As per the Gartland classification system, $46(80.7 \%)$ patients had Type IIIA and 11 (19.2\%) patients had Type IIIB fracture. The average surgical time was $28.3 \pm 1.6$ minutes in Group A and 30 \pm 3.6 minutes in Group B ( $\mathrm{p}=0.02)$. About, 3.5\% patients in Group A had pin loosening. As per the Flynn criteria, $78.6 \%$ in Group A and 79.3\% in Group B had excellent results.

Conclusion: No significant difference in terms of functional and radiological outcome was observed between both the techniques. Thus, both the techniques have equal results.

Key words; supracondylar humerus, percutaneous pinning

Corresponding author : Dr. Mohamed Mahmoud Naeem

Tel.:01002310045

E.mail: naeemmuhammed316@gmail.com
\end{abstract}

\section{INTRODUCTION}

upracondylar fractures of the humerus are the most common elbow injuries in children and make up approximately $60 \%$ of all elbow injuries in the first decade of life ${ }^{[1]}$. These injuries can be one of the most difficult to treat, owing to the presence of associated immediate and late complications like compartment syndrome, neurovascular damage, Volkman's ischaemic contracture and malunion ${ }^{[2-4]}$. These injuries are broadly classified as extension and flexion type with the former being more common ${ }^{[5]}$. Extension injuries are further sub classified as undisplaced fractures (Type I), partially displaced fractures with intact posterior hinge (Type II) and completely displaced fractures (Type III). It was Wilkins ${ }^{[6]}$, who further classified Type III fractures on the basis of coronal displacement as Gartland IIIAposteromedial and IIIB - posterolateral type respectively.

While the general consensus for Type I and few Type II fractures has been closed reduction and cast application, type III fractures usually warrants closed reduction and pinning. Conservative treatment is associated with complications such as loss of reduction, compartment syndrome and malunion ${ }^{[7]}$. The most common choice of pinning are either a medial or a lateral pin in a cross manner or two lateral pins ${ }^{[2,3]}$. Cross pinning has proven to be superior to two lateral pinning with more stability ${ }^{[4,5]}$. However, many surgeons have the opinion that this construct increases the rate of iatrogenic ulnar nerve injury by two to four times ${ }^{[8-11]}$.

The aim of the present study was to compare the functional and radiological outcomes of lateral and cross pinning technique in supracondylar fractures of the humerus in children.

\section{MATERIALS AND METHODS}

A prospective study comprising of 57 cases of displaced fracture supracondylar humerus, treated by lateral and cross pinning, was conducted between May 2016 and May 2018. The inclusion criteria was children with closed extension Type III of supracondylar fracture of humerus. Patients 
with Type I and Type II injuries, flexion type injuries, compound fractures and patients above the age of 13 years were excluded from the study.

All the patients were randomly divided into two groups. The randomization process was done by the odd and even number technique in which the patients with even inpatient numbers were assigned in Group A while the odd inpatient number patients were allotted in Group B. Patients in whom lateral pinning was done were included in Group A $(n=28)$, whereas patients with cross pinning were in Group B $(n=29)$.

All the necessary preoperative work-up was done in the form of thorough clinical and radiological examination. All the fractures were classified using the Gartland's classification system. Well written informed consent was taken and

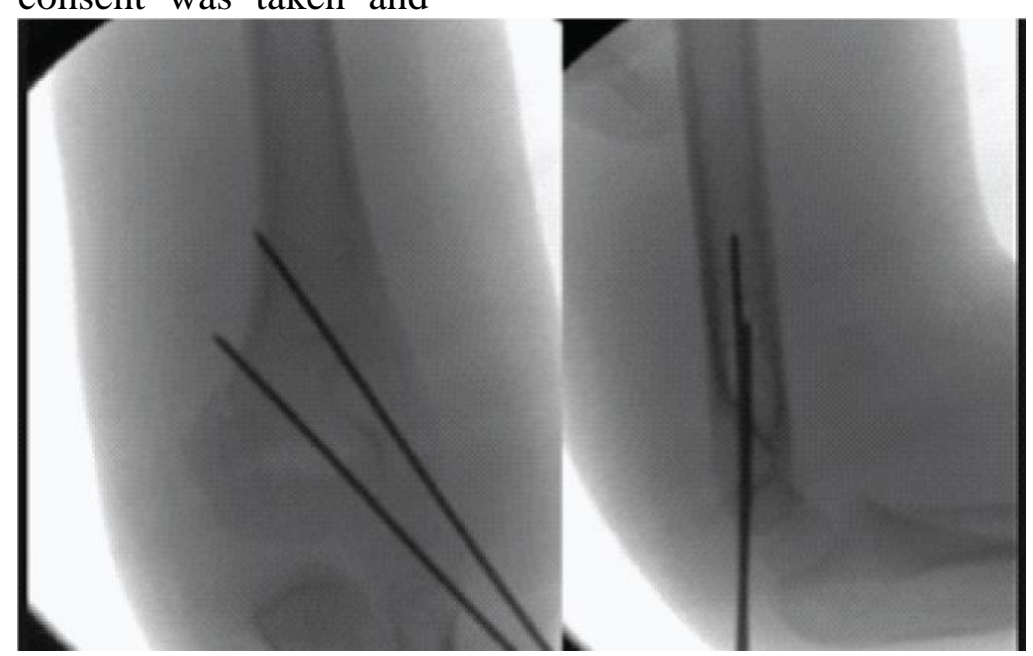

FIG-1: Radiograph with lateral k-wire group A

\section{Operative technique}

Patients were kept in a supine position under general anaesthesia with the injured limb off the table for manipulation and for visualization under $\mathrm{C}$-arm for closed reduction cast or pinning. All the fractures were reduced preoperatively by tractioncountertraction technique and keeping the elbow in hyperflexion with pronation at the forearm. Two $1.6 \mathrm{~mm}$ and $2 \mathrm{~mm} \mathrm{~K}$-wires were used laterally or in the cross manner under C-arm guidance [Fig-1,2]. At the time of insertion of cross wires, a small incision was taken medially and the wire
Ethical Committee approval was obtained from all the patients enrolled in the study. Regular three weekly follow-ups were done till radiological union followed by long- term follow-up at one and two years respectively. The final results were analysed using the Flynn criteria [12]. This criteria is divided into two components, the functional and the cosmetic component and both are further sub-divided as excellent, good, moderate and poor at an interval of five degrees. The functional component consists of measuring the arc of motion in sagittal plane which includes flexion and extension, whereas the cosmetic further measures the carrying angle which indicates the coronal movements at the elbow joint. Greater loss of movements in both, the sagittal as well as coronal plane indicates unsatisfactory outcome.

was inserted as anterior as possible with the elbow in some extension in order to avoid advert injury to the ulnar nerve. After satisfactory reduction, the fracture was held with the $\mathrm{K}$-wires, the wires were bent and cut ends were inserted just beneath the skin. An above elbow splint was then applied at 90 degrees of flexion. Postoperative monitoring to assess the neurovascular status and wound dressing was done on post-operative day two following which all the patients were discharged. 

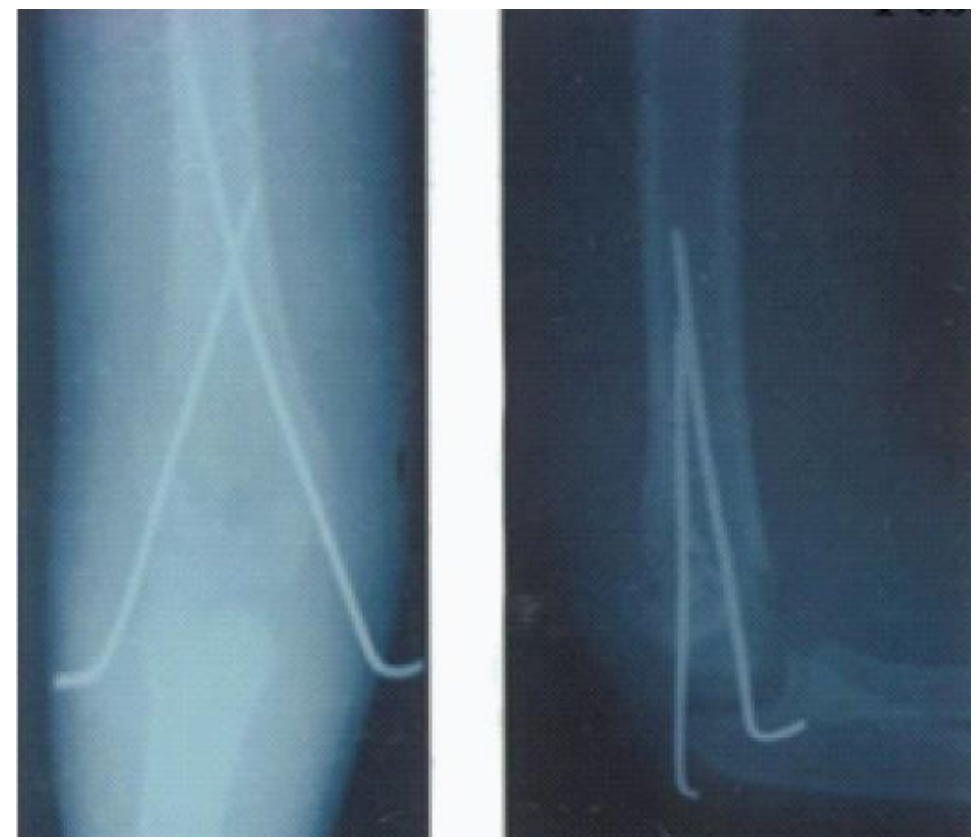

FIG-2: Radiograph with cross k-wire group B

\section{STATISTICAL ANALYSIS}

Independent sample student's t-test was done to assess the parameters like age, follow-up and duration of surgery. The results were expressed as mean with standard deviation and $\mathrm{p}<0.05$ was considered to be statistically significant. The analysis was done using the Epi-info software (Version 3.5.4) and Microsoft Excel 2013 (Microsoft Office version 15.0).

\section{RESULTS}

The mean age of the patients in Group A was $7.20 \pm 2.21$ years and $6.28 \pm 2.03$ years in Group B which was not statistically significant $(\mathrm{p}=0.1)$. There were $21(36.8 \%)$ females and $36(63.2 \%)$ males in the present study. The left side was more commonly involved comprising 32 $(56.14 \%)$ patients. Among the 57 patients enrolled in the study, $46(80.7 \%)$ had a fall while playing, $7(12.2 \%)$ had road traffic accident whereas $4(7.1 \%)$ had fallen from height. As per the Gartland classification system, $46(80.7 \%)$ patients were Type IIIA and $11(19.2 \%)$ patients had Type IIIB fracture. The average surgical time was $28.3 \pm 1.6$ minutes in patients of Group $A$ and $30 \pm 3.6$ minutes in patients of Group $\mathrm{B}$ which was statistically significant $(p=0.02)$. The average follow-up of the patients was $23.4 \pm 1.6$ months in Group A and 22.7 \pm 0.4 months in Group B ( $\mathrm{p}=0.33$ ) [Table-3]. As per the Flynn criteria, $22(78.6 \%)$ patients had excellent, $5(17.9 \%)$ patients had well and $1(3.5 \%)$ patient had an unsatisfactory cosmetic outcome in Group A. The functional factor in Group A was satisfactory in $27(96.4 \%)$ patients. Cosmetic factor was excellent in 23 (79.3\%) and good in $6(20.6 \%)$ patients respectively in Group B. The functional factor was satisfactory in all the patients of Group B. 
Table -3: Demographics and statistics. Statistically Significant*

\begin{tabular}{|c|c|c|c|}
\hline Parameters & GroupA $n=28(\%)$ & GroupB $n=29$ & \\
\hline Age (vears) & $7.20+2.21$ & $6.28+2.03$ & 0.10 \\
\hline \multicolumn{4}{|l|}{ Sex Male Female } \\
\hline & $16(57.1 \%)$ & $20(68.9 \%)$ & \\
\hline \multicolumn{4}{|l|}{ Side Left Right } \\
\hline & $15(53.6 \%)$ & $17(58.6 \%)$ & \\
\hline \multicolumn{4}{|l|}{ Mechanism of injury } \\
\hline Playing & $22(78.5 \%)$ & $24(82.8 \%)$ & \\
\hline Road Traffic Accident & $04(14.3 \%)$ & $03(10.4 \%)$ & \\
\hline Fall from height & $02(7.2 \%)$ & $02(6.8 \%)$ & \\
\hline \multicolumn{4}{|l|}{ type } \\
\hline \multirow[t]{2}{*}{ III A III B } & $22(78.5 \%)$ & $24(82.7 \%)$ & \\
\hline & $06(21.5 \%)$ & $05(17.3 \%)$ & \\
\hline Follow-up (in weeks) & $23.4 \pm 1.6$ & $22.7 \pm 0.4$ & 0.33 \\
\hline Duration of Surgery & $28.3 \pm 1.6 \mathrm{~m}$ & $30 \pm 3.6 \mathrm{~m}$ & \\
\hline (in minutes) & $28.3 \pm 1.6$ & $30 \pm 3.6$ & $0.02 *$ \\
\hline Complications & & & \\
\hline Superficial Infection & $1(3.5 \%)$ & $1(3.4 \%)$ & \\
\hline Ulnar Nerve Neuropraxia & -- & $2(6.8 \%)$ & \\
\hline
\end{tabular}

\section{DISCUSSION}

Supracondylar fracture of humerus has always been one of the most common and challenging fractures among the paediatric age groups. The main goal of the treatment is anatomical reduction and stable internal fixation. Thorough clinical examination is very crucial during the initial assessment of every patient. Closed reduction with Kwires fixation has been the gold standard in the management of these injuries. K-wires have the advantage of ease of use, decreased cost and reduced hospitalization stay ${ }^{[13,14]}$.

The mean age of the patients in the present study was $7.20 \pm 2.21$ years and $6.28 \pm 2.03$ in Group A and B respectively, which was comparable to other studies by Babal JC et al., and Khademolhosseini M et al., [15,16]. Left sided and female gender predominance was also observed in the present study which was also seen by Barr LV et al., in their series of 159 patients ${ }^{[17]}$.

Ulnar nerve neuropraxia has been the major concern in patients where cross pinning configuration has been used. In a series of 375 patients by Lyons JP et al., they observed that $6 \%$ of the patients had an iatrogenic ulnar nerve palsy postoperatively ${ }^{[18] .}$ They also stated that these are usually neuropraxia which resolves almost completely in majority of the situations. There were 25 cases in Group B in the present study, who had ulnar nerve neuropraxia postoperatively and who recovered completely within three weeks of surgery. The incidence of neuropraxia can be reduced by keeping the elbow in 45-50 degrees of flexion rather than the usual hyperflexed position used while inserting the lateral pin. No pin removal was required in the present study for the neuropraxia. In all the patients where cross pinning was executed, a miniopen approach was used, the ulnar nerve was palpated and the $\mathrm{K}$-wire was introduced with the elbow in semiextended position.

There was one patient in each group who had a superficial infection which resolved completely with oral antibiotics. No deep seated infection was observed in 
the present study and no revision surgery was required for it.

There was a statistically significant difference noted in the present study in terms of operative time with longer time required in patients of Group A. The same can be attributed to the fact that medial side required a mini-open approach which increases the overall operative duration.

In the present study, no significant difference was observed in both the groups in terms of the techniques of K-wire insertion. Our results are comparable to the studies by Yen YM and Kocher MS and Reynolds RA et al., who found no significant difference in both the techniques ${ }^{[19,20]}$.

As per the Flynn scoring system, nearly $80 \%$ of the patients in both the groups had excellent results which were comparable to the study by Vito $\mathrm{P}$ et al., who observed more than $90 \%$ excellent results ${ }^{[21]}$.

\section{CONCLUSION}

Pinning for Type III supracondylar fractures of the humerus has proven to be a good option with excellent results. However, as far as the technique is concerned, we observed no significant difference in terms of cosmetic and functional outcome between both the techniques.

\section{REFERENCES}

1. Herring JA. Tachdjian's Pediatric Orthopaedics. 3 rd ed. Vol; 3. Philadelphia: W.B. Sanders; 2002. Fracture about the elbow; pp.2139-221.

2. Kocher MS, Kasser JR, Waters PM, Syder BD, Hresko MT, Hedequist D, et al. Lateral entry compared with medial and lateral pin fixation for completely displaced supracondylar humeral fractures in children. A randomized clinical trial. J Bone Joint Surg Am. 2007;89(4):706-12.

3. Ramachandran M, Skaggs DL, Crawford HA, Eastwood DM, Lanlode FD, Vitale $\mathrm{MG}$, et al. Delaying treatment of supracondylar fractures in children: has the pendulum swung too far? J Bone Joint Surg Br. 2008:90(9):1228-33.

4. Kruschemandl I, Aldrian S, Kottstorfer J, Seis A, Thalhammer G, Egkher A. Crossed pinning in paediatric supracondylar humerus fractures: a retrospective cohort analysis. Int Orthop. 2012;36(9)1893-98.

5. Pellegrin DM, Brivio A, Pescatori E, Tessari L. Supracondylar humerus fractures in children: Closed reduction and cross pin fixation in prone position. GIOT. 2008;34:199-204.

6. Wilkins KE. The operative management of supracondylar fractures. Orthop Clin North Am. 1990;21(2):269-89.

7. Brauer CA, Lee BM, Bae DS, Waters PM, Kocher MS. A systematic review of medial and lateral entry pinning versus lateral entry pinning for supracondylar fractures of the humerus. J Pediatr Orthop. 2007;27(2):181-86.

8. Dua A, Eachempati K, Malhotra R, Sharma L, Gidaganti M. Closed reduction and percutaneous pinning of displaced supracondylar fractures of humerus in children with delayed presentation. Chin J Traumatol. 2011;14(1):14-19.

9. Kim WY, Chandru R, Bonshahi A, Patron RW. Displaced supracondylar humeral fractures in children: results of a national survey of paediatric orthopaedic consultants. Injury. 2003;34(4):274-77.

10. Lee SS, Mahar AT, Miesen D, Newton PO. Displaced pediatric supracondylar humerus fractures: biomechanical analysis of percutaneous pinning techniques. J Pediatr Orthop. 2002;22(4):440-43.

11. Woratanarat $\mathrm{P}$, Angsanuntsukh $\mathrm{C}$, Rattanasiri S, Thakkinstian A. Metaanalysis pf pinning of supracondylar fracture of the humerus in children. $\mathbf{J}$ Orthop Trauma. 2012;26(1):48-53.

12. Flynn JC, Mattews JG, Benoit RL. Blind pinning of displaced supracondylar fractures of the humerus in children. Sixteen years experience with long-term follow-up. J Bone Joint Surg Am. 1974;56(2):263-72.

13. Saha RL. Percutaneous K-wire fixation in paediatric supracondylar fractures of humerus: A retrospective study. Niger Med J. 2013;54(5):329-34.

14. Slobogean BL, Jackman H, Tennant S, Slobogen GP, Mulpuri K. Iatrogenic ulnar nerve injury after the surgical treatment of displaced supracondylar fractures of the humerus: Number needed to harm, a systematic review. J Pediatr Orthop. 2010;30(5):430-36.

15. Babal JC, Mehlman CT, Klein G. Nerve 
injuries associated with pediatric supracondylar humeral fractures: A metaanalysis. J Pediatr Orthop. 2010;30(3):25363.

16. Khademolhosseini M, Abd Rashid AH, Ibrahim S. Nerve injuries in supracondylar fractures of the humerus in children: is nerve exploration indicated? J Pediatr Orthop B. 2013;22(2):123-26.

17. Barr LV. Paediatric supracondylar humeral fractures: epidemiology, mechanisms and incidence during school holidays. J Child Orthop. 2014;8(2):167-70.

18. Lyons JP, Ashley E, Hoffer MM. Ulnar nerve palsies after percutaneous crosspinning of supracondylar fractures in children's elbows. J Pediatr Orthop.
1998;18(1):43-45.

19. Yen YM, Kocher MS. Lateral entry compared with medial and lateral entry pin fixation for completely displaced supracondylar humeral fractures in children. Surgical technique. J Bone Joint Surg. Am. 2008;90(2):20-30.

20. Reynolds RA, Jackson H. Concept of treatment in Supracondylar humeral [20] fractures. Injury. 2005;36(1):A51-56.

21. Vito P, Riccioli M, Gianluca T, Ludovico L, Cristo C, Condorelli G, et al. Surgical treatment of displaced supracondylar pediatric humerus fractures: comparison of two pinning techniques. J Funct Morphol Kinesiol.

2016;1:39-47. 